\title{
The Factors of Perception of Images of Chinese Images in Transbaikalie
}

\author{
Zhukov Artyem Vadimovich \\ Department of Philosophy, Sociological Faculty, Transbaikal State University, Russia
}

Copyright $(2015$ by authors, all rights reserved. Authors agree that this article remains permanently open access under the terms of the Creative Commons Attribution License 4.0 International License

\begin{abstract}
The article is devoted to the theme connected with population mentality aspects' investigation, which exists under conditions of Russian-Chinese transboundary relations at the territory of Transbaikalie. The author reveals the essence of such notions as, «mentality of Transbaikal citizens» and «mythological image»; he also investigates the peculiarities of perception of Chinese images and image of China by mass consciousness of non-Chinese peoples of this transboundary region. The aim and novelty of the work is defined by the fact that it is the first attempt of complex investigation of the phenomenon mythology study in respect to China at the territory of Transbaikalie. The author's allocation of the main construction and reproduction factors of mythological Chinese images spreading is the result of the work. The author suggests the phenomenon «culture boundaries of China» as an aspect of Chinese culture influence, which not only creates an obstacle, but simultaneously serves the point of contact between different nations, cultures and languages, creating thereby an active zone of mythology study on China.
\end{abstract}

Keywords Mentality of Transbaikal Citizens, Mythological Images of China, Culture Boundaries of China, Historic-cultural Identifications, Ethno-cultural Interrelations, Transboundary Region, Intercultural Dialogue

\section{Relevance of Research of Processes of Perception of an Image of China}

The interest to China is very actual today as these territories are in direct contact, more than that the presence of a powerful civilization with its five thousand history and the richest cultural traditions is specially felt there. Enormous attention to the current affairs taking place in the neighbouring state is accompanied by the permanent interest to the ideology and culture of ancient and middle-aged China, to the past of the great Chinese nation [15, p.7]. Contemporary Russian people, living at the territory of
Transbaikalie are the successors of Russian as well as the eastern culture. That's why the image influence on them related with China has deep roots and connection which finds itself in regional archetypes and traditions of world perception. The subject of our analyses is mental constructions distributed among the Russian population of Transbaikalie which includes information about China and Chinese people regarded as mythological images. In the paragraph devoted to the methodological aspects of the research, we have made an attempt to answer the questions: Under which circumstances do the Russians perceive China as one image and the Chinese as another? Why the population of Transbaikalie has a peculiar tradition of this nation's perception?

The leading method of research is the factorial analysis which represents a technique of complex studying and the analysis of impact of factors on formation of features of mythological perception of China by the population of Transbaikalia. As a result of the analysis factors receive the quantitative and quality standard showing influence of a concrete factor on formation of result. The structure of research is supplemented typological and comparative-historical with methods. The typological method is the basis for identification of the basic mythological types which are the center of images of perception of China. Application of a comparative-historical method recognizes that in development new elements are formed from already existing in the course of what evolution of initial structure reveals. By means of the comparative and comparative analysis the common and peculiar features of reproduction of mythological elements in consciousness of the population of Transbaikalia at different stages of its development come to light.

Turning to the mentality of Transbaikal citizens analyses, we believe that mentality is the existing social psychology and individual values' system [11, p.39] which differs in diversity not only of individuals, but different social and gender groups of population as well [4, p.56]. The word «mentality» means the set of world perceptions and frames of mind which are peculiar to individuals or people's groups describing the things occurrence in the environment. The 
portrait of national and group mentality is created by social believes including emotional, rational and over-rational notions. The researchers point out the presence of permanent interconnection of mentality with language systems used by a population because language is the reflection of mentality's development in memory [7, p. 37].

\section{Theoretical Bases of Research of Mythological Influence of China}

We believe that the factors influencing on our life are the circumstances which in turn influence the transformation of views and believes of population such as geopolitical conditions of population's urbanism, their cultural contacts, and also experience allowing to interpret the affairs differently, to make forecasts, planning and motivate the further actions. The most evident answer to the question why the means of world perception and mentality of various nations differ from each other is the statement that they do not coincide in the sphere of symbolic system, language which store and develop these systems [19, p.87]. In the language display of everyday life though such phenomena as animation of ideas, personification of fates, materialization of grief, turning an argument into some weapon; people usually demonstrate the display of mythological consciousness. The names of these communities are preserved in written sources which help us to learn about the existence of nations' names, i.e. about their historic-cultural identities reflecting the neighbours' ideas on their essence $[11$, p.30]. It should be taken into consideration that modern methodological developments of mythology study refer a part of social consciousness to the myth in which man transfer from the old times his own qualities to natural objects, imputing to them life and man's feelings as well as the most modern part of ideology, when something abstract and obscure is endowed by the qualities of live nature, man himself or something that is opposed to man.

One of the main functions of mentality is the perception of oneself and nations which surrounds him. A proper image is created in the nation's mentality which reveals itself as a legend stored in unsophisticated world picture and as any other legend is a certain myth. In myths people more often identify themselves with self-presentation - highly organized community which differs in positive characteristics of «own» people. From ancient times these communities were surrounded by other people whom we distinguish as «Alien» and even «Not being people». The perception of image «Alius» is traditionally connected with functioning of mythological consciousness in science, the main function of which is transit, identification of differently planned contents or to be more correct, images.

Most of the citizens of the Transbaikal region know that the Russians and Chinese people have different mentality from their own experience. Touristic and business trips to China allow to learn the exotics, more than that they partly help to state differences of various video products about
China: news in mass media, documentary and feature films. The specifics of the Chinese mentality we learn through comparative study at the everyday level of symbolic systems of the Russian and Chinese cultures - rituals, architecture, cuisine and language. Even this domestic study proves that Russian and Chinese people have different perceptions of the same things. For example, for the Russians government embodies an image of in an awkward and ferocious bear, moving cumbersome, ineffective, but dangerous machine for people $[27$, p. 146]. On the contrary for the Chinese the personification of state embodies some care about people by the gods.

Thus, it should be noted that there is significant difference between these philosophical systems. As a result there exists an embodied in images a set of associations, the identification of which is connected with the need to perceive and comprehend the phenomenon of China through everyday life and reality of the Russians. China is in this case something which exists on the other side of the border. Life of its inhabitants is perceived as life of the inhabitants of the other world and it is reflected in minds of the Russians, firstly, as a reflection of the real world surrounding the Russians, and secondly - by turning to fantasy and fiction, whose functioning is based on the observation of China and the Chinese, and on the basis of interaction experience with them [9, p. 7]. Accordingly, the formation of abstract symbols, expressed in narratives and concretized in giving estimates in relation to China, occurs later, and the determination of their value depends on personal beliefs of the authors.

\section{Major Factors of Formation of an Image of China in Transbaikalia}

The processes of Chinese mythological images penetration into the minds of the population of Transbaikalie were historically influenced by several factors, the most significant of which is geopolitical situation in the region. It occupies one of the most strategically important areas of Eurasia, formed at the boundary of the largest natural landscape areas and sub-continents extra-tropical North Central Asia interaction [26, p. 4]. China presents the largest of the neighboring oriental civilizations for Transbaikalie. Its northern borders are the contact zones of religious, inter-civilized dialogue with cultures of the peoples of the region $[13$, p. 43]. Despite the specificity of the Chinese civilization, which is distinguished by their mentality, religion, life's ideals, cultural values, traditions, language, etc. since ancient times, historically there is a sphere of ethnic and cultural interaction, which invariably arises between China and the surrounding nations.

This sphere is associated with the concept of interstate and cultural boundaries. In the context of the discourse devoted to the analysis of the peoples' consciousness of Transbaikalie and Chinese culture interaction, it is necessary to highlight such aspects as «visible» and «promising», that 
is «foreign». According to Bulgakov, mythmaking products constitute a meeting and border between the worlds: by the immanent of everyday consciousness and unattainable $[5, \mathrm{p}$. 116]. They play a significant role in determining the parameters of synchronous interaction. Furthermore, they are markers that divide this space into two poles. In our case, one pole corresponds to everyday reality in which people live Transbaikalie, on the other China is placed, the main attribute of which image has always been unfathomable mystery of Chinese culture. «Border» is the most essential element of this space description. At the same time the notion of border with «unattainable» is ambiguous, because only one side of it is the delimiter, but on the other - it is linked with that which has not been yet known. Yu. M. Lotman notes that the border that divides the inner world of the individual («my») and outer space («foreign»), gives rise to religion and culture [18, p. 483 ], but in fact it gives rise to the myth. At the borders with China, it is the most creative point myth creation about China.

Phenomenal consciousness of man is a borderland zone, and in this context it becomes a space of various mythologies existence associated with the sphere, which is situated abroad. This fact connects concepts such as «myth» and «mystery» disclosed in the monograph by V.M. Naydysha. In relation to the borderland reality of China, theoretical propositions given by Naydysha V.M. allows us to say that «myth of China» is as a mystery, which beyond the border with China, is existential dimension of human existence on this side of the border. Mysterious events occurring abroad, accompanying this mystery, are essential for the initiation of myth creation. Myth creation tool is a rational solution of the conflict «Secrets of China» in this case, which is abroad, and «Problems presented by China», which is on the other side of the border. Availability of an opportunity to rationalize the existence of secrets is defined by irrational need to experience the mysteries of consciousness by the people living on the other side of the border [23, p. 533]. In other words, there is a variety of situations in life where it becomes necessary to point out something that defies rational explanation, but the result of a dialogue with that is abroad is not something obvious. Then myth creation comes into play, but when China is abroad, and then myth creation about China comes into play.

The second important factor that determines the occurrence of myth creation about China in the Transbaikal region is the fact that the use of language, in which people mix conscious and unconscious layers of their consciousness into a single blending. Even during the period of anthropological knowledge foundation development, E. Taylor substantiated a position according to which different ethnic groups live, obeying the same laws, performing the tasks of survival, safety, and welfare of procreation. A. Maslow agrees with this statement, and he has formulated a universal model of needs, which does not report to national specificity [20, p. 64]. Positive social science data suggest that in particular, rather than invented, mythologized world does not have much in common. Differences are revealed in how different people, using language, describe their existence, i.e. in their images and myths.

In the context of intercultural issues, held in the Chinese border zone, it is important to understand that people of Transbaikalie had close interaction with the Chinese civilization. However, despite rather long and close contact of these cultures, there exist a small number of Chinese words in the languages ethnic groups of Transbaikalie. Especially few of them are in Russian language [23, p. 145]. This is explained by the fact that in most cases of interethnic communication, the Chinese themselves were taught customs and languages of the peoples with whom they had to establish contacts. In this case, the Chinese have practically removed all benefits of their civilization, leaving for unenlightened neighbours an opportunity to explain and think about themselves in their native language [24, p. 206]. In particular, the Russians of Transbaikalie always tried to communicate with the Chinese in Russian, not trying to learn Chinese, which entailed the problem of interpretation, i.e. translation and has become a prerequisite for ethnic myth creation. An example that symbolizes this trend is the story of embassy cossack Ivan Petlin who brought a letter of China Emperor Zhu Yiyun in 1619, in which the emperor allowed to send the Russians embassies and make trade with China. Due to the Russians' ignorance of Chinese language, the letter laid in the embassy untranslated and represented the unresolved riddle (up until N. Spafary did not translate it). As a result an idiom had come into the Russian language «Chinese letter» [25, p. 40].

Today narratives common at the level of everyday, mass consciousness, with a high degree of probability reflecting ideas about what people are the Chinese, must be determined as a myth, at least because the presentation and verbal expressions of the Chinese about themselves differ from them. Therefore, to compare these submissions opposed is practically an important task.

The third factor is the penetration of images of China into Transbaikalie which had begun in the Bronze Age. The region was involved in the development of Central Asian civilization, being the separate historical and cultural region [21, p. 131]. From its side, the space adjacent to the Lake Baikal, for a long time are some of the most important and interesting for China, invariably claim to increase its influence in Central Asia. Since ancient times China has been a source of a peculiar myth creation. This phenomenon is associated with a lot of stories about gods, invisible spirits and heroes which have a profound effect on the mind and hearts of the people, and not only the Chinese people [9, p. 8].

Therefore, despite the fact that the tribes inhabiting the region since ancient times differed in militancy and uncontrollability, the processes of interaction and exchange of various mythological ideas had consistently held between them and China. Chinese interests in the Transbaikal region during this period faced with tribes of mass Turko- Mongols and Tungus- speaking nomads $[6, p .5]$. Since that time, as the Central Asian countries, their cultures and religions 
historically had an impact on the consciousness of Transbaikalie, imagery, springing from the origins of Chinese culture, reflected itself in the most significant ideological symbols [12, p. 113]. The studies show that the imagery of Transbaikalie, as well as that of the peoples of Central Asia, was significantly influenced by two ideas that originated in the Chinese culture. The most prominent place belongs to the idea of worshiping Heaven in the person of the emperor acting as the son of Heaven. It became a cult of Eternal Blue Sky and the hero born by a virgin for the peoples of the region. The second idea, which came from China, has been associated with distributed Lamaism priests worshiping local spirits and the spirits of ancestors. It possessed a special place in the cult of Tibetan Buddhism, supported on the territory of Transbaikalie and Mongolia by the Manchu government [1, p. 9].

The fourth, is an important factor determining the characteristics of processes of penetration and assimilating of Chinese images by the population of Transbaikalie. It was the accession of these territories to Russia in the XVII century and their subsequent coexistance. Russia is one of the largest multi-national states, preserving specific characteristics of folk and religious cultures. Russian people are the largest Russian [ 17, p. 292], who, for various reasons, arrived to the territory of Transbaikalie, and had faced here with the prevailing ideological complex, the elements of which for a long time were the images and symbols associated with China. It is important to note that integration processes under conditions of the region led to the fact that while creating joint survival, the representatives of various ethnic and religious groups had formed a certain mental unity, including the likelihood of mixed coexistence of different ideological structures. Today the Russians, among which two subjects of inter-ethnic interaction the Russians and the Buryats, live in Transbaikalie. Two peoples have known each other for a long time. The history of their close inter-group communication has more than three hundred years. Therefore, despite the fact that among some of them there exists a presence of a complex of network identifications, however, the predominant is general identification, defining and those and others as «Russians», to which the other ethnic groups had joined. By the present time, most of ethnic groups that have entered into active interaction processes in XVII-XIX centuries, in Transbaikalie merged into externally single territorial community, referred to as «Transbaikalians» $[8$, p. 175]. The term «Transbaikalians» not only means the place of living, they possess their own mentality [14], the main characteristic of which is tolerance that has developed as a result of interaction between different worlds. In community of the Transbaikalians is a reflection of community and, at the same time, recognition of ethnic diversity of many people living in this region. At the same time all these groups in the region allocate one ethnic neighbour, the Chinese, who is in the same area, but nevertheless, always understood as «Alien». With respect to him as a «Stranger» different kinds of ethnic «stereotypes» and prejudices spread among the
Transbaikalians. It is important for us to realize that we conduct surveys of perception image "Alien», which is perceived, and then represented in the minds of people and nations, understood as «Own».

The fifth development factor of the mentioned processes of interfaith interaction in modern Transbaikalie is the processes of interaction between world globalizing, Russian and Chinese cultures. The trends towards globalization of socio-cultural life of many Transbaikalians lead to the abandonment of the old ideological orientations and crisis of national and cultural identity. Due to the changing value orientations are exposed to rethinking the traditional values of life and search of new, effective values. Among these values, proposed by China, one of the leading civilizations in the world, its culture and religions possess not the last place [3, p. 240]. Beginning of the XXI century was marked by the increasing influence of China for the Transbaikalians, economic and cultural expansion of which manifests itself in many spheres of the world civilization. This fact is noticed by well-known sinologist A.G. Larin, according to whom, the Russians are characterized by panic because of the Chinese activity in the territories, which are increasingly fall outside the scope of Russian interests [16, p. 94]. This objective leads to a burst of activity around the myth creation, its culture, ethnic representatives.

\section{Let's Summarize the Results:}

1. Formation of mythological images of China in the Transbaikal region is specified by several factors, among which are geopolitical factor, indicating the position of the region border between Russia and its European - oriented culture and language, and China, whose influence has been dominant for a long time in Central Asia. The presence of the «border» of cultures not only creates a barrier, but also serves as a meeting point of different cultures and languages, thereby forming the most active zone of myth creation about China.

2. World of reception of Chinese culture in the Transbaikal region is this mythological world that significantly differs from that in which the Chinese are phenomenally live. Images of China and the Chinese people created by population of the Transbaikalie are characterized by the presence of hidden behind the external manifestations of myths, intentions, which will inevitably lead to the formation of a multiplicity of conflicting connotations for a regional concept of China. The impact on this sphere makes not only the ability of population to have an ambiguous reception of China image, but China's own myth creation activity whose ideas and images for a long time are projected into the consciousness of population in Transbaikalie. Thus, the presence of divergent receptions of mythological images of China and the Chinese in the minds of population of the regions is inevitable and natural. Chinese mythological images present in most spheres of life of the population in the Transbaikal region and this fact shows the variety and 
diversity of Chinese culture.

\section{REFERENCES}

[1] Abayev N. V. Archaic forms of religion and Tengriism in a Internal Asia. Ulan-Ude, 2015. 275.

[2] Bazarov B. D. The sacraments and the practice of shamanism. Ulan-Ude, 2009. 208.

[3] Bertrong D. Confucianism. M., 2004. 304 p.

[4] Bodriyar Zh. Consuming Society. Its myths and structures. M, 2006. 269p.

[5] Bulgakov S.N. Unfading light: contemplation and speculation. M., 2001. $572 \mathrm{c}$.

[6] Buryats / Main Ed. L.L. Abaeva, N.L. Zhukovskaya. Moscow, 2004. $633 \mathrm{p}$.

[7] Vasileva K.K. Mentality: ontogeny and ethnological dimension (on the example of the Buryat ethnic group). Moscow, 2002. 200.

[8] Vassilieva, K.K., SA Melnitskaya Socio-cultural mentality societies of Transbaikal Territory. Chita, 2008. 210.

[9] Verner E. Myths and Legends of China. M., 2007. 400.

[10] Vitkovskaya D., Zh. Zayonchkovskaya New Stolypin's policy in the Far East of Russia: Hopes and Reality // Perspectives of the Far Eastern region: cross-country interaction. M., 1999. Pp. 80-121.

[11] Golovanivskaya M.K. Mentality in the mirror of a language. Some basic philosophical concepts of French and Russian. Moscow, 2009. 376 p.

[12] Grach A.D. Central Asia - the general and special combined social and geographical factors //The role of geography in the history of pre-capitalist societies (ethnographic data). L.: 1984. Pp. 113-125.

[13] Eremkina T.A. Traditions of interethnic relations in the regional dimension on the example of the Transbaikal Territory // Contemporary world politics: perspectives from Asia. 24-25 September 2010 Chita -M., 2010. Pp. 43-45.

[14] Konstantinov M.V. Transbaikalians. [Electronic resource]: Encyclopedia of Transbaikalie. URL: http://encycl.chita.ru/e ncycl/concepts/?id=1949. (date of access: 27/11/2015 )

[15] Kychanov E.I. The history of the border with China, ancient and medieval states (from the Huns to the Manchus). SPb., 2010. 364 .

[16] Larin A.G. Russian-Chinese relations and Chinese migrants in the evaluation of the Russians (continued) // Problems of the Far East. 2008. Number 6. Pp. 81-95.

[17] Loginov A.V. Multifaith // Encyclopedia of Russia. Moscow, 2001. Pp. 292-293.

[18] Lotman Semiosphere. St. Petersburg. 2010. 704.

[19] Luriya A.R. Language and consciousness. M., 1998. 336.

[20] A.H. Maslow Theory of human motivation. M., 1999. 218.

[21] Mikhailov T.M. Buryat ethnic group in the light of contemporary social change // Republic of Buryatia - a state within the Russian Federation. Ulan-Ude, 1998. Pp. 130-145.

[22] Morozova V.S. Regional culture in socio-cultural space of the Russian and Chinese border: diss. doctor. philosophical sciences. Chita, 2013. 183.

[23] Naydysh V.M. Philosophy of mythology. From Antiquity till the Romantic era. Moscow, 2002. 544.

[24] Osokin G.M. Muscoviya in the East. M., 1996. 221.

[25] Pokrovsky F.I.Travel to Mongolia and China of Siberian cossack Ivan Petlin in 1618. SPb., 1914 . Pp. 39-40.

[26] Natural environment and man in Pleistocene (Western Transbaikalie and South - Eastern Baikal area)/ L.V. Lbov [and others.] Ulan-Ude, 2003. 208.

[27] Tarasova E.A. National features of an image of power in the culture of modern Russia and China: Comparative Analysis // Russia and China: history and prospects of cooperation: Materials 2 International. Conf. Blagoveshchensk, 2012 pp. 140-146. 